\title{
Influence of Styrene-Acrylic Ester Dispersion on the Early Hydration of Cement
}

\author{
Ru Wang and Xiaoxin Shi \\ Key Laboratory of Advanced Civil Engineering Materials of Ministry of Education, School of Materials Science and Engineering, \\ Tongji University, 4800 Cao'an Road, Shanghai 201804, China
}

Correspondence should be addressed to Ru Wang; ruwang@tongji.edu.cn

Received 20 May 2014; Accepted 16 July 2014; Published 11 August 2014

Academic Editor: Jaehwan Kim

Copyright (C) 2014 R. Wang and X. Shi. This is an open access article distributed under the Creative Commons Attribution License, which permits unrestricted use, distribution, and reproduction in any medium, provided the original work is properly cited.

Early hydration of cement in the presence of styrene-acrylic ester (SAE) dispersion was investigated, and the hydration heat, hydration degree, and hydrates were analyzed using isothermal calorimeter, XRD, and ESEM. The results show that SAE dispersion prolongs the induction period, postpones and shortens the accelerating period, and inhibits the decelerating and stable periods of cement hydration. The hydration heat and hydration degree of cement in the presence of SAE dispersion are less than those of the control. SAE dispersion inhibits the formation of $\mathrm{C}_{4} \mathrm{AH}_{13}$ and thus $\mathrm{AFt}$, and more SAE dispersion brings stronger influence, but it enhances the stability of AFt. AFt generation during the early hydration period is controlled gradually by the reaction of $\mathrm{C}_{4} \mathrm{AH}_{13}$ generation with increasing SAE dispersion, but this is controlled by the reaction of $\mathrm{C}_{4} \mathrm{AH}_{13}$ consumption for the control paste. Besides, SAE dispersion retards and inhibits the formation of $\mathrm{CH}$ and $\mathrm{C}-\mathrm{S}-\mathrm{H}$ and also changes their morphology.

\section{Introduction}

It is well known that polymers can improve the toughness, bond strength, impermeability, frost resistance, and many physical properties of the cement-based materials [1-5]. That is why polymer-modified cement mortar is being more and more widely used in many applications such as tile adhesives, frontage coatings, coverings, and repair mortar. Commonly, application of cement-based material resulted from its property, whereas the property is related with the structure which depends mostly on the cement hydration. In order to develop more advantages of polymer-modified cementbased materials, many investigations have been conducted to figure out the hydration mechanism of cement in the presence of polymers. At present, styrene-butadiene rubber (SBR), styrene-acrylic ester copolymer (SAE), ethylene-vinyl acetate copolymer (EVA), polyacrylic ester (PAE), and vinyl acetate and versatate copolymer (VA/VeoVa) are widely used in polymer-modified cement-based materials in China. Therefore, it is important to research the physical and chemical influences of these polymers on cement hydration due to their diverse structures and physical properties [6].
Different polymers have various functions on the cement hydration. Some researches $[7,8]$ found that polyvinyl alcohol (PVA) or other water-soluble polymers could slow down the early hydration of cement. Piqué et al. [9] found that PVA prolonged cement hydration because the gel formed by PVA hinders cement hydration. Zhang and Wang [10] thought hydroxyethyl methyl cellulose (HEMC) retarded the hydration of cement in early ages because of the interactions between HEMC and the cement hydrates but has little effect on cement hydration after the decelerating period. Betioli et al. [11, 12] found that HMEC could greatly prolong the induction period of cement hydration but EVA only has a very slight influence on the same period. $\mathrm{R}$. Wang and $\mathrm{P}$. M. Wang [13] observed that SBR dispersion and powder accelerated the formation of AFt within 28 days and greatly inhibit $\mathrm{CH}$ within 3 days. Yang et al. [14] suggested that SBR led to denser and more refined microstructure of the cement mortar after 28 days, which was also found to promote the formation of AFt and facilitate chloride binding. The research of Wang et al. [15] showed that SAE redispersible powder accelerates the formation of AFt and enhances its stability and restrains $\mathrm{CH}$ content within 28 days. It has also been found 
TABLE 1: Chemical composition of the P.II 52.5 Portland cement (\% by weight).

\begin{tabular}{lccccccccc}
\hline $\mathrm{CaO}$ & $\mathrm{SiO}_{2}$ & $\mathrm{Al}_{2} \mathrm{O}_{3}$ & $\mathrm{Fe}_{2} \mathrm{O}_{3}$ & $\mathrm{MgO}$ & $\mathrm{SO}_{3}$ & $\mathrm{~K}_{2} \mathrm{O}$ & $\mathrm{Na}_{2} \mathrm{O}$ & $\mathrm{TiO}_{2}$ & $\mathrm{f}-\mathrm{CaO}$ \\
\hline 63.72 & 21.24 & 6.35 & 3.40 & 1.28 & 2.22 & 0.62 & 0.38 & 0.32 & 0.28 \\
\hline
\end{tabular}

TABle 2: Mineral composition of the P.II 52.5 Portland cement (\% by weight).

\begin{tabular}{lllll}
\hline $\mathrm{C}_{3} \mathrm{~S}$ & $\mathrm{C}_{2} \mathrm{~S}$ & $\mathrm{C}_{3} \mathrm{~A}$ & $\mathrm{C}_{4} \mathrm{AF}$ & $\mathrm{CaSO}_{4}$ \\
\hline 58.29 & 17.12 & 9.77 & 10.58 & 3.96 \\
\hline
\end{tabular}

that the addition of ethylene/lauric acid vinyl ester/vinyl chloride copolymer postponed the formation of $\mathrm{AFt}, \mathrm{CH}$, and $\mathrm{C}-\mathrm{S}-\mathrm{H}$ gel and decreased their content greatly within 1 day [16]. Silva et al. [17] researched that EVA dispersion promoted the generation of AFt and declined $\mathrm{CH}$ content within 28 days due to the chemical reaction of $\mathrm{Ca}^{2+}$ with EVA.

From previous researches, it can be found that polymers have strong influences on the hydration of cement as well as hydrates, especially the early periods. Though some valuable conclusions have been achieved through the researches, it is still hard to form a systematic mechanism of the whole cement hydration process using present results, especially for the early hydration. Therefore, this paper will research the early hydration of cement in the presence of SAE dispersion, which is a widely used economic polymer and was found good at reducing the shrinkage, improving the fracture resistance and increasing the bending and tensile strengths of cement mortar $[18,19]$. The function mechanism of SAE dispersion in the early hydration of cement will be discussed from the point of hydration kinetics in intensive hydration time. The isothermal calorimeter, X-ray diffractometer (XRD), and environmental scanning electron microscope (ESEM) were used in this investigation.

\section{Experiment}

2.1. Raw Materials. Materials used included P.II 52.5 Portland cement, styrene-acrylic ester (SAE) dispersion, and deionized water. The chemical and mineral compositions of the cement are shown in Tables 1 and 2. The properties of styrene-acrylic dispersion are displayed in Table 3.

2.2. Preparation of Specimens. The water/cement ratio by mass $\left(m_{w} / m_{c}\right)$ of all the samples in this experiment was kept at 0.4. SAE dispersion (only solid part in the dispersion was calculated and the water in the dispersion was calculated into water to cement ratio)/cement ratios by mass $\left(m_{p} / m_{c}\right)$ were $0 \%, 5 \%, 10 \%, 15 \%$, and $20 \%$. Specimens to be tested were prepared by mixing the SAE dispersion with water firstly and then adding cement. All specimens were cured at the environment of $20^{\circ} \mathrm{C} / \mathrm{RH} 90 \pm 5 \%$ to designed ages.

After curing, samples for XRD analysis were taken at a depth of more than $1 \mathrm{~mm}$ from the surfaces of the specimens, broken into pieces, and immersed in the ethyl alcohol to stop the cement hydration. The ethyl alcohol was replaced every day lasting as long as one week. The samples were then vacuum-oven-dried at $45^{\circ} \mathrm{C}$ until their mass was constant, after which they were ground to powders. Samples for morphology observation using ESEM needed no special treatment, and only a small block from the center of the cured sample was required.

2.3. Test Methods. The heat evolution of cement hydration was measured with Sweden Thermalmat TAM Air 08 isothermal calorimeter. The testing time is as long as 3 days and data is recorded every minute.

XRD analysis was conducted using a Rigaku D/max 2550 $\mathrm{X}$-ray diffractometer with graphite-monochromatized $\mathrm{CuK} \alpha$ radiation generated at $40 \mathrm{kV}$ and $200 \mathrm{~mA}$. Time-fixed step scanning was carried out, with a step length of $0.02^{\circ}$, a 4 second settle time for each step, and a scanning range of $8^{\circ}-$ $13^{\circ}$ and $17^{\circ}-19^{\circ}$.

The Quanta 200F ESEM was used in this investigation to observe the micromorphology.

\section{Results and Discussions}

3.1. Heat Evolution. Heat evolution is an important method to characterize the cement hydration process and the hydration heat mainly comes from the reactions of the cement. Figure 1 shows the heat evolution rate of cement hydration with and without SAE dispersion. The heat evolution rate of all the cement pastes increases immediately after mixing with water and reaches a maximum after 3 or 4 minutes and then decreases gradually with the time prolongation. It is found that SAE dispersion has little effect on the very initial period of hydration. However, it does prolong the induction period of cement hydration from 0.9 hours of the control paste to about 1.6, 2.3, 2.5, and 2.6 hours of the pastes at the $m_{p} / m_{c}$ of $5 \%, 10 \%, 15 \%$, and $20 \%$, respectively (Figure $1(\mathrm{a})$ ). It indicates that SAE dispersion prolongs the induction period of cement hydration. The more the SAE dispersion is, the longer the induction period lasts.

As shown in Figure 1(b), SAE dispersion amount has prominent influence on the accelerating period of cement hydration. The more the SAE dispersion is, the shorter this period is. The accelerating period for the control paste lasts about 10 hours while it keeps about 7.5, 5.8, 5.6, and 4.5 hours for the cement pastes at the $m_{p} / m_{c}$ of $5 \%, 10 \%, 15 \%$, and $20 \%$, respectively. Besides, the corresponding exothermic peak also decreases sharply with the growing SAE dispersion. It is known that the C-S-H gel and $\mathrm{CH}$ from the hydration of $\mathrm{C}_{3} \mathrm{~S}$ mainly grow in the accelerating period and this period is decided by the chemical reactions. Therefore, it greatly 
TAble 3: Properties of styrene-acrylic (SAE) dispersion.

\begin{tabular}{lccccc}
\hline Solid content $(\%)$ & Average particle size $(\mu \mathrm{m})$ & Viscosity $(\mathrm{mPa} \cdot \mathrm{s})$ & $\mathrm{pH}$ value & Lowest film-forming temp. $\left({ }^{\circ} \mathrm{C}\right)$ & Glass transition temp. $\left({ }^{\circ} \mathrm{C}\right)$ \\
\hline 57 & 0.2 & $300-750$ & $7.0-8.5$ & 1 & -6
\end{tabular}
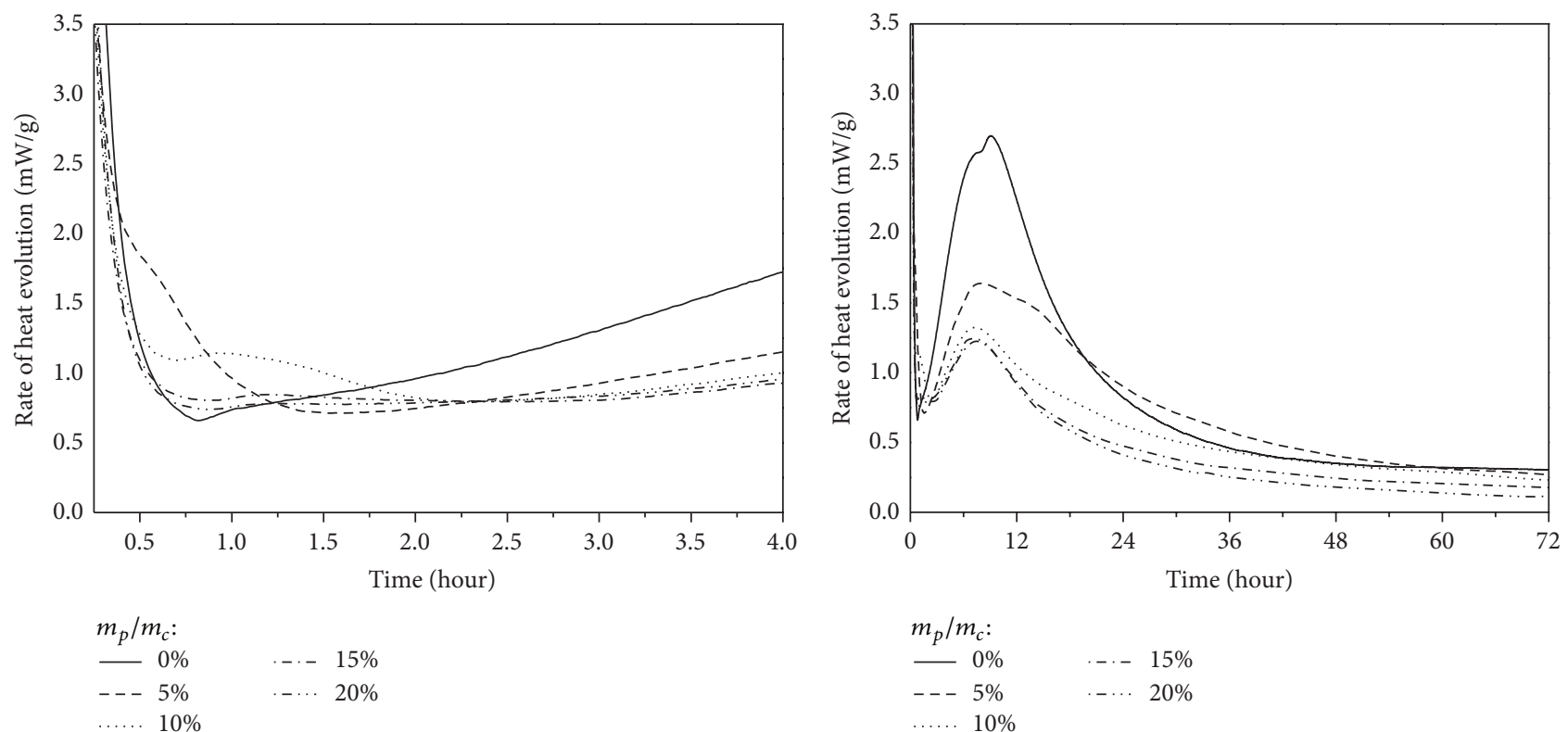

$$
\begin{aligned}
& m_{p} / m_{c}: \\
& \text { - } 0 \% \text {-. } 15 \% \\
& \text { - - } 5 \% \quad \text {. - . } 20 \% \\
& \text {..... } 10 \%
\end{aligned}
$$

(a)

(b)

FIGURE 1: Rate of heat evolution of cement hydration in different $m_{p} / m_{c}$.

demonstrates that SAE dispersion inhibits the chemical reactions and thus the hydration of $\mathrm{C}_{3} \mathrm{~S}$.

In the decelerating and stable periods (Figure 1(b)), the heat evolution rate of most pastes with SAE dispersion is less than that of the control paste within 3 days and the rate is declining with the increasing $m_{p} / m_{c}$. According to cement hydration theory, the total hydration during the decelerating and stable periods is controlled by the ions diffusion speed and AFt also tends to transform to AFm in this period. So, it can be concluded that the addition of SAE dispersion slows down the ions diffusion speed during these periods because of the absorption of SAE dispersion on cement particles and formed polymer film, which will be shown later by ESEM observations in the paper.

Figure 2 exhibits the hydration heat of cement in different $m_{p} / m_{c}$. It is easy to see that, with more SAE dispersion in the cement paste, the hydration heat is less and less, showing the negative effect of SAE dispersion on the cement hydration. Table 4 is the hydration degree of cement in different $m_{p} / m_{c}$. The hydration degree is calculated according to formula (1) [20]. The complete cement hydration heat for unit mass of the used cement is $493 \mathrm{~J} / \mathrm{g}$ based on Tables 1 and 2 . The hydration degree of all cement pastes grows with the hydration time indicating that hydration reactions happen continuously during the early 3 days. In addition, the hydration degree with increasing SAE dispersion is less and less in the same age showing the retardation effect of SAE dispersion on the cement hydration. Here is a significant decline of the hydration degree when the $m_{p} / m_{c}$ increases from 0 to $15 \%$. However, the decreasing degree is not big anymore when the $m_{p} / m_{c}$ increases from $15 \%$ to $20 \%$. This states that an excess amount of SAE dispersion when the $m_{p} / m_{c}$ is higher than $15 \%$ does not change the cement hydration significantly any more. Consider

$$
\begin{gathered}
\alpha(t)=\frac{H(t)}{H_{c}} \\
H_{c}=500 w\left(\mathrm{C}_{3} \mathrm{~S}\right)+260 w\left(\mathrm{C}_{2} \mathrm{~S}\right)+866 w\left(\mathrm{C}_{3} \mathrm{~A}\right) \\
+420 w\left(\mathrm{C}_{4} \mathrm{AF}\right)+624 w\left(\mathrm{SO}_{3}\right)+1186 w(\mathrm{f}-\mathrm{CaO}) \\
+850 w(\mathrm{MgO}),
\end{gathered}
$$

where $\alpha(t)$ is hydration degree at $t$ time, $H(t)$ is cement hydration heat for unit mass of cement at $t$ time $(\mathrm{J} / \mathrm{g}), H_{c}$ is complete cement hydration heat for unit mass of cement $(\mathrm{J} / \mathrm{g})$, and $w$ is the mass fraction of the mineral or oxide in cement.

From the heat evolution analysis, it can be drawn that SAE dispersion not only retards the cement hydration but also inhibits it within 3 days.

3.2. Hydrates of Calcium Aluminate. Researching the cement hydrates is helpful for understanding the hydration process. The hydrates of calcium aluminate are investigated using XRD analysis. XRD patterns of cement pastes with SAE 


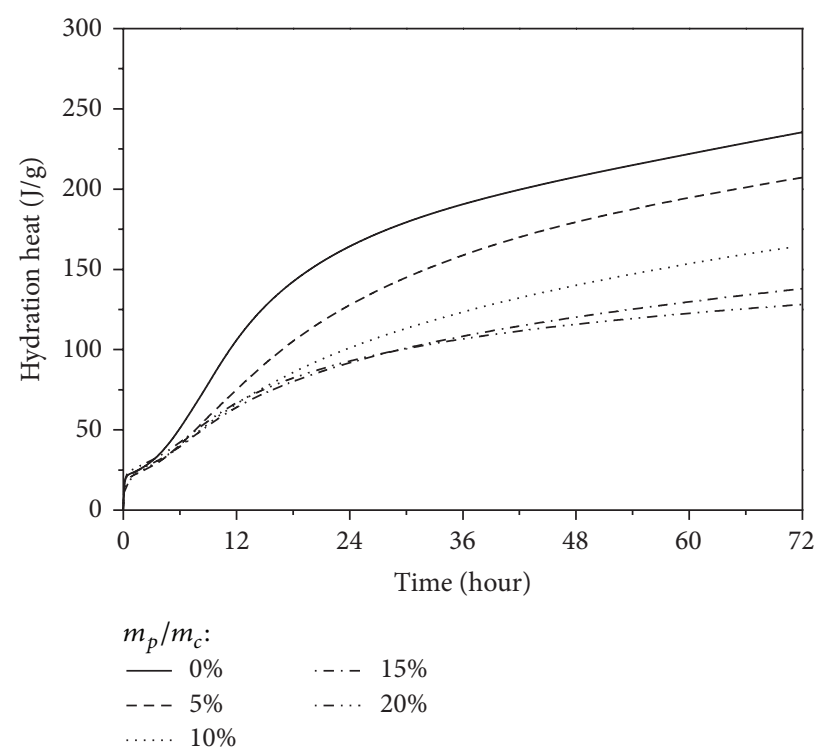

FIgURE 2: Hydration heat of cement in different $m_{p} / m_{c}$.

TABLE 4: Hydration degree of cement in different $m_{p} / m_{c}(\%)$.

\begin{tabular}{lllllll}
\hline Hydration time (hours) & 12 & 24 & 36 & 48 & 60 & 72 \\
\hline$m_{p} / m_{c}$ & & & & & & \\
$0 \%$ & 21 & 33 & 39 & 42 & 45 & 48 \\
$5 \%$ & 15 & 26 & 32 & 36 & 39 & 42 \\
$10 \%$ & 13 & 21 & 25 & 28 & 31 & 33 \\
$15 \%$ & 13 & 19 & 22 & 24 & 26 & 28 \\
$20 \%$ & 13 & 19 & 22 & 23 & 25 & 26 \\
\hline
\end{tabular}

dispersion in different $m_{p} / m_{c}$ at $2 \theta$ range of $8^{\circ} \sim 13^{\circ}$ are displayed in Figure 3. The diffraction peak at about $9.1^{\circ}$ relates to the diffraction of (100) crystal plane of AFt [21]. The appearing diffraction peak at about $11.6^{\circ}$ is corresponding to $\mathrm{C}_{4} \mathrm{AH}_{13}$. The diffraction peak of (020) crystal plane of $\mathrm{C}_{4} \mathrm{AF}$ at about $12.2^{\circ}$ is evident in all pastes, which shows the slow hydration of it. There is only slightly promotion effect of SAE dispersion on $\mathrm{C}_{4} \mathrm{AF}$ hydration.

The software MDI Jade 6.5 is used to analyze the special diffraction peaks of $\mathrm{AFt}$ and $\mathrm{C}_{4} \mathrm{AH}_{13}$ quantitatively and the results are listed in Tables 5 and 6 . The integrated intensity of AFt has different changing trend with the $m_{p} / m_{c}$ with hydration time change. After 10 minutes, AFt content of all pastes with SAE dispersion is less than that in the control paste but the difference is not significant. With hydration time passing by, AFt content in the pastes with $m_{p} / m_{c}$ of $5 \%$ and $10 \%$ grows more than the control one after 1 hour. When the $m_{p} / m_{c}$ is $15 \%$, AFt content becomes more than that in the control one after 1 day. After 3 days, AFt content in all the modified pastes is higher than that in the control paste. It expresses that in the early ages of the experiment SAE dispersion promotes AFt content when the $m_{p} / m_{c}$ is lower but inhibits it at higher $m_{p} / m_{c}$; in relative older ages of the experiment, for all used $m_{p} / m_{c}$ the SAE dispersion promotes the AFt content. The more AFt content in the modified pastes in the older ages can be explained that SAE dispersion enhances the stability of AFt, inhibiting the transformation from AFt to AFm. More SAE dispersion means stronger enhancement of the stability. This is beneficial to the volume stability of cement-based material.

Another hydrate of calcium aluminate, $\mathrm{C}_{4} \mathrm{AH}_{13}$, is the hydrate from the reaction of $\mathrm{C}_{3} \mathrm{~A}$ and $\mathrm{Ca}(\mathrm{OH})_{2}(\mathrm{CH})$ like (2) and it is only observed in some pastes and specific ages because it is also involved in the generation of AFt as (3), showing that it is an intermediate hydrate. But some interesting phenomena were found during the research. In Figure 3, the diffraction peak of $\mathrm{C}_{4} \mathrm{AH}_{13}$ only appears in the following cases: control paste after 10 minutes, $1,4,6$, and 8 hours; modified paste at the $m_{p} / m_{c}$ of $5 \%$ after 10 minutes, 1 , 4,6 , and 8 hours; modified paste at the $m_{p} / m_{c}$ of $10 \%$ after $1,4,6,8$, and 12 hours; modified paste at the $m_{p} / m_{c}$ of $15 \%$ after 6 hours. The peak has never been seen in the modified paste at the $m_{p} / m_{c}$ of $20 \% . \mathrm{C}_{4} \mathrm{AH}_{13}$ content of the control paste increases to the highest and then decreases. It means the generation of $\mathrm{C}_{4} \mathrm{AH}_{13}$ is easier than the consumption of it during this period and AFt content is controlled by the reaction in (3). When adding SAE dispersion, the appearance of $\mathrm{C}_{4} \mathrm{AH}_{13}$ peak is gradually put off to 1 hour and 6 hours or even hard to be observed with the $m_{p} / m_{c}$ increasing. Even if the $\mathrm{C}_{4} \mathrm{AH}_{13}$ peaks of the paste at the $m_{p} / m_{c}$ of $5 \%$ and the control paste appear simultaneously, the peak intensity of the modified paste is weaker than that in the control. This shows that the speed of reaction in (2) is slower little by little until the generation of $\mathrm{C}_{4} \mathrm{AH}_{13}$ is slower than the consumption of it in the reaction in (3) at larger $m_{p} / m_{c}$, at which time the AFt content is controlled by the reaction in (2) instead of that in 

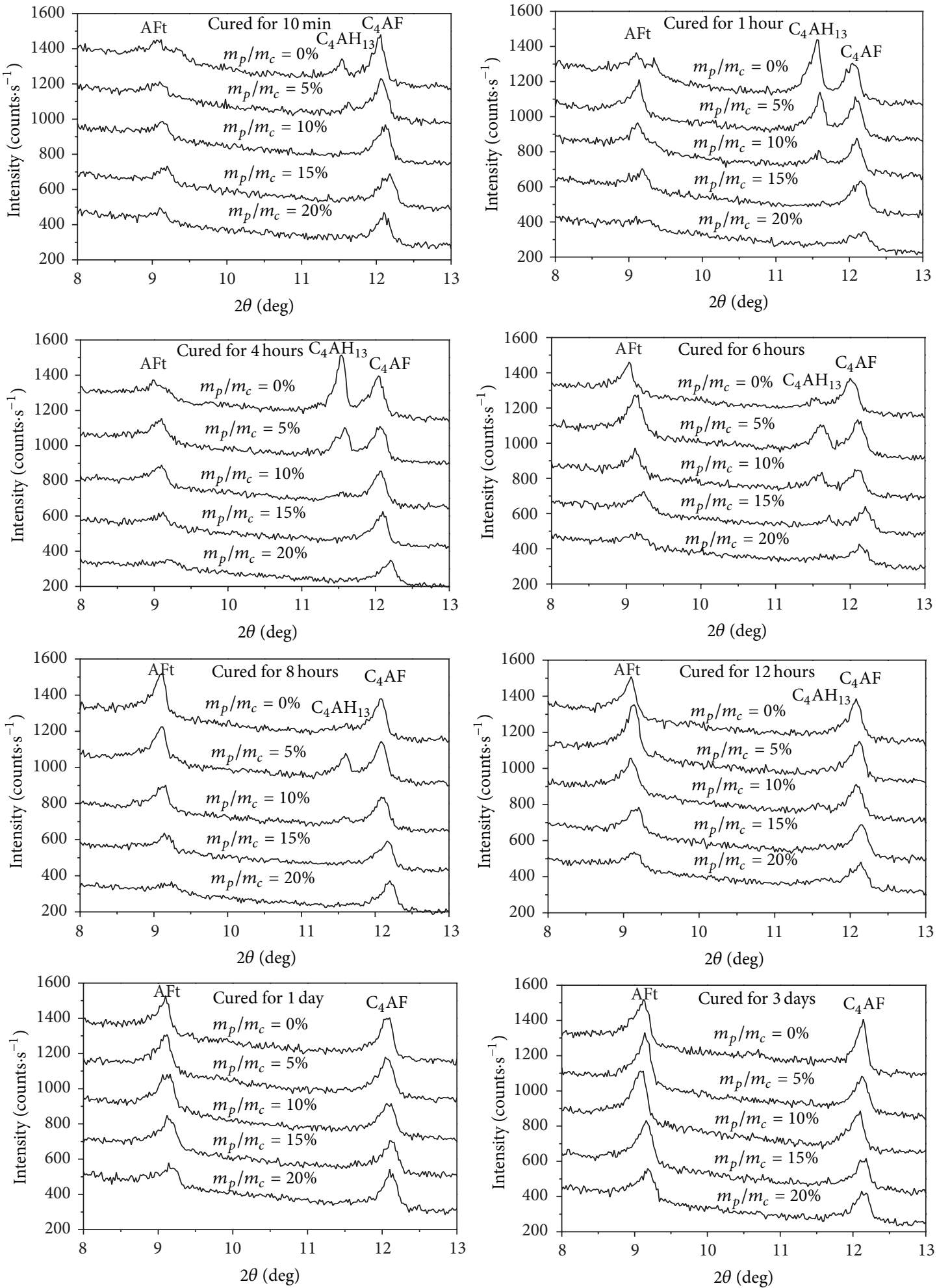

FIGURE 3: XRD patterns of cement pastes with SAE dispersion at $2 \theta$ range of $8^{\circ}-13^{\circ}$. 
TABLE 5: The integrated results of XRD peak of AFt in the pastes with SAE dispersion.

\begin{tabular}{|c|c|c|c|c|c|}
\hline Curing time & $m_{p} / m_{c}$ & $d(\AA)$ & $I_{\max }\left(\right.$ counts $\left.\cdot \mathrm{s}^{-1}\right)$ & $I_{\text {integ }}\left(\right.$ counts $\left.\cdot \mathrm{s}^{-1}\right)$ & $R$ \\
\hline \multirow{5}{*}{10 minutes } & $0 \%$ & 9.696 & 374 & 2396 & 1.00 \\
\hline & $5 \%$ & 9.709 & 255 & 1623 & 0.72 \\
\hline & $10 \%$ & 9.668 & 311 & 1983 & 0.91 \\
\hline & $15 \%$ & 9.606 & 319 & 2041 & 0.98 \\
\hline & $20 \%$ & 9.704 & 222 & 1411 & 0.71 \\
\hline \multirow{5}{*}{1 hour } & $0 \%$ & 9.712 & 461 & 2783 & 1.00 \\
\hline & $5 \%$ & 9.675 & 618 & 3977 & 1.50 \\
\hline & $10 \%$ & 9.688 & 471 & 3023 & 1.19 \\
\hline & $15 \%$ & 9.623 & 374 & 2293 & 0.95 \\
\hline & $20 \%$ & 9.525 & 139 & 975 & 0.42 \\
\hline \multirow{5}{*}{4 hours } & $0 \%$ & 9.762 & 320 & 2043 & 1.00 \\
\hline & $5 \%$ & 9.671 & 473 & 3452 & 1.77 \\
\hline & $10 \%$ & 9.667 & 414 & 2654 & 1.42 \\
\hline & $15 \%$ & 9.723 & 276 & 1832 & 0.98 \\
\hline & $20 \%$ & 9.627 & 170 & 1072 & 0.64 \\
\hline \multirow{5}{*}{6 hours } & $0 \%$ & 9.692 & 495 & 3192 & 1.00 \\
\hline & $5 \%$ & 9.651 & 825 & 5320 & 1.75 \\
\hline & $10 \%$ & 9.565 & 374 & 3386 & 1.17 \\
\hline & $15 \%$ & 9.687 & 459 & 2672 & 0.96 \\
\hline & $20 \%$ & 9.629 & 194 & 1226 & 0.46 \\
\hline \multirow{5}{*}{8 hours } & $0 \%$ & 9.795 & 596 & 3882 & 1.00 \\
\hline & $5 \%$ & 9.71 & 742 & 4783 & 1.29 \\
\hline & $10 \%$ & 9.688 & 509 & 4362 & 1.24 \\
\hline & $15 \%$ & 9.647 & 321 & 2527 & 0.60 \\
\hline & $20 \%$ & 9.585 & 167 & 1151 & 0.36 \\
\hline \multirow{5}{*}{12 hours } & $0 \%$ & 9.711 & 814 & 4073 & 1.00 \\
\hline & $5 \%$ & 9.669 & 1091 & 7050 & 1.82 \\
\hline & $10 \%$ & 9.709 & 672 & 6032 & 1.63 \\
\hline & $15 \%$ & 9.626 & 533 & 3426 & 0.97 \\
\hline & $20 \%$ & 9.647 & 301 & 1921 & 0.57 \\
\hline \multirow{5}{*}{1 day } & $0 \%$ & 9.711 & 649 & 3967 & 1.00 \\
\hline & $5 \%$ & 9.711 & 783 & 6183 & 1.64 \\
\hline & $10 \%$ & 9.688 & 714 & 5971 & 1.66 \\
\hline & $15 \%$ & 9.667 & 660 & 5523 & 1.60 \\
\hline & $20 \%$ & 9.646 & 342 & 2186 & 0.66 \\
\hline \multirow{5}{*}{3 days } & $0 \%$ & 9.731 & 572 & 3594 & 1.00 \\
\hline & $5 \%$ & 9.667 & 1048 & 6772 & 1.98 \\
\hline & $10 \%$ & 9.731 & 1064 & 6439 & 1.97 \\
\hline & $15 \%$ & 9.646 & 960 & 6202 & 1.98 \\
\hline & $20 \%$ & 9.625 & 586 & 3766 & 1.26 \\
\hline
\end{tabular}

$d$ : interplanar spacing; $I_{\max }, I_{\text {integ }}$ : intensities of XRD pattern for maximum and integrate; $R=I_{\text {integ }}\left(1+m_{p} / m_{c}\right) /\left(I_{\text {integ }}\right)_{\text {control }}$.

(3) in the control. It can be concluded that SAE dispersion changed the controlling factor of AFt generation. Consider the following:

$$
\begin{gathered}
\mathrm{C}_{3} \mathrm{~A}+\mathrm{CH}+12 \mathrm{H}=\mathrm{C}_{4} \mathrm{AH}_{13} \\
\mathrm{C}_{4} \mathrm{AH}_{13}+3 \mathrm{C} \overline{\mathrm{S}} \mathrm{H}_{2}+14 \mathrm{H}=\mathrm{C}_{3} \mathrm{~A} \cdot 3 \mathrm{C} \overline{\mathrm{S}} \cdot \mathrm{H}_{32}+\mathrm{CH}
\end{gathered}
$$

3.3. Hydrates of Calcium Silicate. $\mathrm{CH}$ is an important hydrate of calcium silicate of the cement, which can reflect the hydration of calcium silicate to some extent, so the quantitative analysis of it is carried out. $\mathrm{CH}$ can come from the reactions seen in (4) to (5). But it is mainly the hydrate of $\mathrm{C}_{3} \mathrm{~S}$ within 3 days in (4) because $C_{2} S$ has an extremely slow hydration rate during this period. Figure 4 gives XRD patterns of cement pastes with SAE dispersion in different curing ages 
TABLE 6: The integrated results of XRD peak of $\mathrm{C}_{4} \mathrm{AH}_{13}$ in the pastes with SAE dispersion.

\begin{tabular}{|c|c|c|c|c|c|}
\hline Curing time & $m_{p} / m_{c}$ & $d(\AA)$ & $I_{\max }\left(\right.$ counts $\left.\cdot \mathrm{s}^{-1}\right)$ & $I_{\text {integ }}\left(\right.$ counts $\left.\cdot \mathrm{s}^{-1}\right)$ & $R$ \\
\hline \multirow{2}{*}{10 minutes } & $0 \%$ & 11.539 & 336 & 2146 & 1.00 \\
\hline & $5 \%$ & 11.621 & 198 & 1250 & 0.62 \\
\hline \multirow{3}{*}{1 hour } & $0 \%$ & 11.559 & 708 & 4676 & 1.00 \\
\hline & $5 \%$ & 11.600 & 532 & 3385 & 0.79 \\
\hline & $10 \%$ & 11.580 & 164 & 933 & 0.22 \\
\hline \multirow{3}{*}{4 hours } & $0 \%$ & 11.539 & 941 & 6045 & 1.00 \\
\hline & $5 \%$ & 11.598 & 605 & 3876 & 0.68 \\
\hline & $10 \%$ & 11.541 & 122 & 764 & 0.14 \\
\hline \multirow{4}{*}{6 hours } & $0 \%$ & 11.539 & 180 & 1140 & 1.00 \\
\hline & $5 \%$ & 11.601 & 522 & 3353 & 3.05 \\
\hline & $10 \%$ & 11.702 & 195 & 1933 & 1.19 \\
\hline & $15 \%$ & 11.582 & 308 & 1967 & 1.97 \\
\hline \multirow{3}{*}{8 hours } & $0 \%$ & 11.619 & 127 & 794 & 1.00 \\
\hline & $5 \%$ & 11.600 & 498 & 3195 & 4.12 \\
\hline & $10 \%$ & 11.582 & 118 & 739 & 1.02 \\
\hline 12 hours & $10 \%$ & 11.618 & 106 & 660 & - \\
\hline
\end{tabular}

$d$ : interplanar spacing; $I_{\max }, I_{\text {integ }}$ : intensities of XRD pattern for maximum and integrate; $R=I_{\text {integ }}\left(1+m_{p} / m_{c}\right) /\left(I_{\text {integ }}\right)_{\text {control }}$.

and different $m_{p} / m_{c}$ at $2 \theta$ range of $17^{\circ} \sim 19^{\circ}$. The special diffraction peak at about $18^{\circ}$ is ascribed to the diffraction of (001) crystal plane of $\mathrm{CH}$. The software MDI Jade 6.5 is also applied to integrate the intensity of the diffraction peak quantitatively and the results are listed in Table 7. In Figure 4, there is nearly no $\mathrm{CH}$ diffraction peak after 10 minutes and 1 hour, which is because it is in the initial and induction periods of cement hydration proved by the heat evolution measurement. During this period, the concentration of $\mathrm{Ca}^{2+}$ is less than the saturated level and $\mathrm{CH}$ is hard to precipitate. Even if there is some $\mathrm{CH}$, it is quickly consumed in the generation of $\mathrm{C}_{4} \mathrm{AH}_{13}$. However, the diffraction peak of $\mathrm{CH}$ starts to emerge after 6 hours and the content of $\mathrm{CH}$ increases gradually with the prolongation of hydration time whatever with or without SAE dispersion. It means that the hydration degree of $\mathrm{C}_{3} \mathrm{~S}$ of all pastes grows with time passing. The $\mathrm{CH}$ peak of the control paste appears after 6 hours and the earliest obvious appearance of $\mathrm{CH}$ peak in the pastes with SAE dispersion is after 12 hours, showing that SAE dispersion retards the hydration of $\mathrm{C}_{3} \mathrm{~S}$ and this can also be proved by the delayed appearing time of accelerating period in the modified pastes in the heat evolution curves. What is more, $\mathrm{CH}$ content decreases with the increasing $m_{p} / m_{c}$. For example, the content of $\mathrm{CH}$ at the $m_{p} / m_{c}$ of $5 \%, 10 \%, 15 \%$, and $20 \%$ is $0.89,0.69,0.34$, and 0.24 times that of the control paste after 3 days. It indicates that the addition of SAE dispersion restrains the hydration of $\mathrm{C}_{3} \mathrm{~S}$ which is in accordance with the results of heat evolution measurement, that is, the shorter accelerating period and smaller corresponding exothermic peak. Therefore, the delayed formation of $\mathrm{CH}$ and its less content in early ages will result in the slow hardening and strength development of the cement-based material:

$$
\begin{aligned}
& \mathrm{C}_{3} \mathrm{~S}+n \mathrm{H}=\mathrm{C}-\mathrm{S}-\mathrm{H}+(3-x) \mathrm{CH} \\
& \mathrm{C}_{2} \mathrm{~S}+m \mathrm{H}=\mathrm{C}-\mathrm{S}-\mathrm{H}+(2-x) \mathrm{CH}
\end{aligned}
$$

3.4. Morphology Observation. ESEM is a very useful and visual method to observe the morphology of the cement hydrates without destroying its structure. It has been proved that SAE dispersion has some effects on the hydration process and hydrates content. Some of these influences can also be observed by ESEM more vividly. Figure 5 shows the ESEM images of cement pastes in the absence and presence of SAE dispersion. Some regular and irregular shape hydrates are observed on the surface of cement particles in the control paste after 10 minutes (Figure 5(a)). Most of the regular shape hydrates, covered on the surface of the cement, belong to AFt which were also detected using XRD. At the same time, it is clear that SAE dispersion particles cover not only the surface of the cement particles but also the space among the cement particles in the paste with SAE dispersion (Figure 5(b)).

After 1 hour, much lamellar $\mathrm{C}_{4} \mathrm{AH}_{13}$ can be observed in the control paste (Figure 5(c)), showing that the hydration of $\mathrm{C}_{3} \mathrm{~A}$ happened greatly at this time. While adding SAE dispersion, it is easy to see that SAE particles on the surface of the cement but lamellar $\mathrm{C}_{4} \mathrm{AH}_{13}$ tend to grow around the space among the cement particles (Figure 5(d)). The $\mathrm{C}_{4} \mathrm{AH}_{13}$ content now is much less than that in the control one which is in accordance with XRD analysis results.

After 6 hours, C-S-H gel is more obvious in the control paste indicating it has been in the accelerating period of cement hydration and the shape of it is short cluster (Figure 5(e)). $\mathrm{C}_{4} \mathrm{AH}_{13}$ is hard to find, meaning that most has been consumed. On the contrary, there is nearly no obvious $\mathrm{C}-\mathrm{S}-\mathrm{H}$ gel in the paste with SAE dispersion but some $\mathrm{C}_{4} \mathrm{AH}_{13}$ exists (Figure 5(f)). What is more, the SAE dispersion particles on the surface of cement particles become not clear and form film structure partly.

The C-S-H gel continues to develop and cluster-like gel becomes the main component after 12 hours. The outline of it is better than that after 6 hours in the control paste 

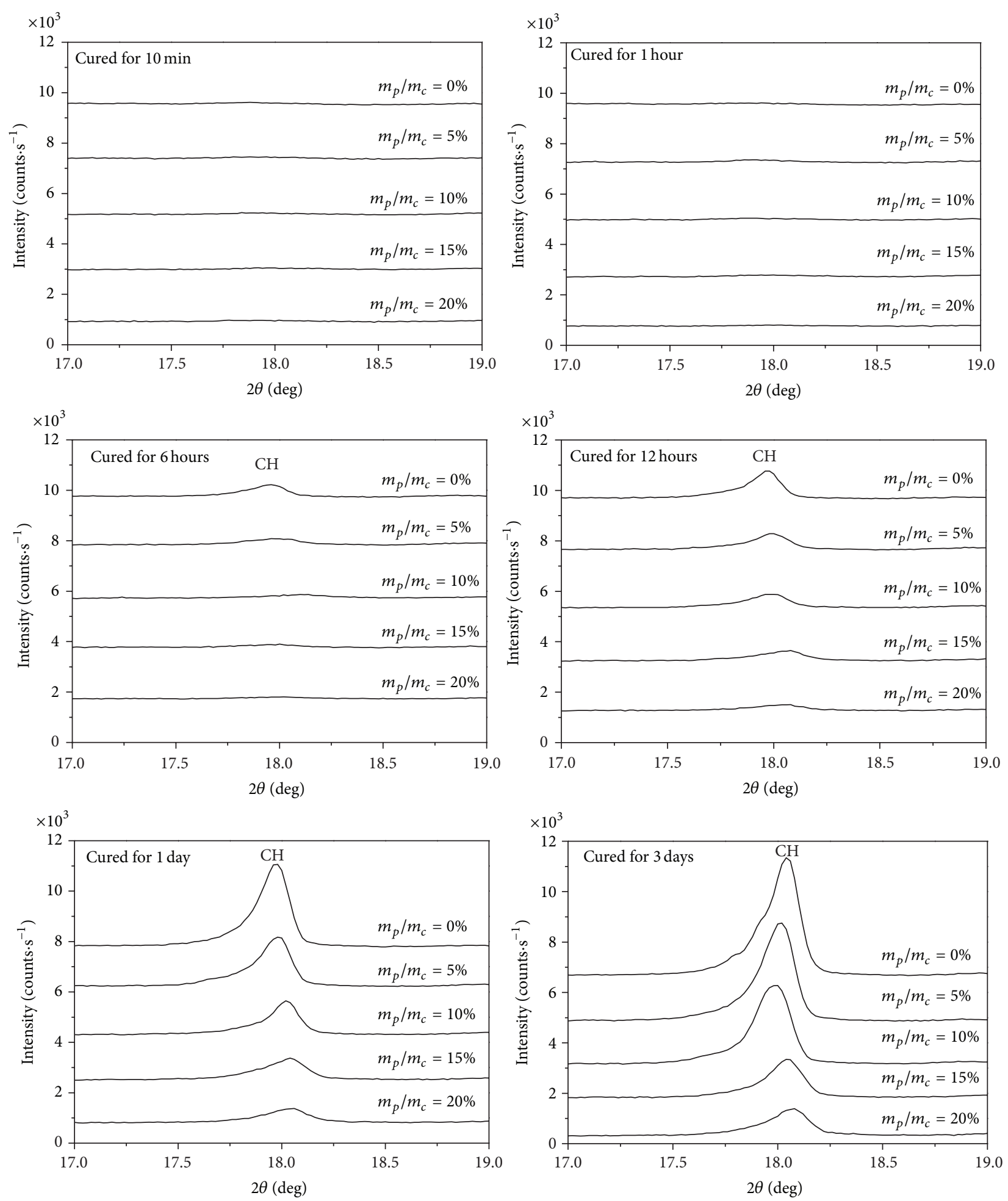

FIGURE 4: XRD patterns of cement pastes with SAE dispersion at $2 \theta$ range of $17^{\circ}-19^{\circ}$.

(Figure 5(g)). When adding SAE dispersion, cluster-like C-S$\mathrm{H}$ gel also appears which replaces SAE particles and $\mathrm{C}_{4} \mathrm{AH}_{13}$ present after 6 hours, and meantime some polymer films are observed on the surface of the hydrates (Figure 5(h)). However, the C-S-H gel content is much less and its appearing time is delayed from 6 to 12 hours compared with the control one, which confirms the effect trend of SAE dispersion on the calcium silicate hydrates formation analyzed by XRD.

The C-S-H gel gets closer with some rod-like AFt and these hydrates mutually penetrate to form a composite 
TABLE 7: The integrated results of XRD peak of $\mathrm{CH}$ in the pastes with SAE dispersion.

\begin{tabular}{|c|c|c|c|c|c|}
\hline Curing time & $m_{p} / m_{c}$ & $d(\AA)$ & $I_{\max }\left(\right.$ counts $\left.\cdot \mathrm{s}^{-1}\right)$ & $I_{\text {integ }}\left(\right.$ counts $\left.\cdot \mathrm{s}^{-1}\right)$ & $R$ \\
\hline \multirow{5}{*}{6 hours } & $0 \%$ & 4.935 & 1793 & 11619 & 1.00 \\
\hline & $5 \%$ & 4.934 & 850 & 5488 & 0.50 \\
\hline & $10 \%$ & 4.887 & 484 & 3107 & 0.29 \\
\hline & $15 \%$ & 4.925 & 433 & 2775 & 0.27 \\
\hline & $20 \%$ & 4.919 & 224 & 1425 & 0.15 \\
\hline \multirow{5}{*}{12 hours } & $0 \%$ & 4.934 & 2944 & 19117 & 1.00 \\
\hline & $5 \%$ & 4.924 & 1568 & 10151 & 0.56 \\
\hline & $10 \%$ & 4.929 & 1237 & 8002 & 0.46 \\
\hline & $15 \%$ & 4.903 & 1512 & 6794 & 0.41 \\
\hline & $20 \%$ & 4.904 & 875 & 5651 & 0.35 \\
\hline \multirow{5}{*}{1 day } & $0 \%$ & 4.935 & 11123 & 72423 & 1.00 \\
\hline & $5 \%$ & 4.930 & 5482 & 35650 & 0.52 \\
\hline & $10 \%$ & 4.919 & 3660 & 23780 & 0.36 \\
\hline & $15 \%$ & 4.913 & 2246 & 14568 & 0.23 \\
\hline & $20 \%$ & 4.908 & 2165 & 14042 & 0.23 \\
\hline \multirow{5}{*}{3 days } & $0 \%$ & 4.935 & 13424 & 87422 & 1.00 \\
\hline & $5 \%$ & 4.913 & 11530 & 75080 & 0.89 \\
\hline & $10 \%$ & 4.925 & 9087 & 59146 & 0.69 \\
\hline & $15 \%$ & 4.913 & 4044 & 26276 & 0.34 \\
\hline & $20 \%$ & 4.903 & 2777 & 18023 & 0.24 \\
\hline
\end{tabular}

$d$ : interplanar spacing; $I_{\max }, I_{\text {integ }}$ : intensities of XRD pattern for maximum and integrate; $R=I_{\text {integ }}\left(1+m_{p} / m_{c}\right) /\left(I_{\text {integ }}\right)_{\text {control }}$.

microstructure in the control paste after 1 day (Figure 5(i)). But SAE dispersion changes the morphology of C-S-H gel, making it become curly in the modified paste (Figure 5(j)). The C-S-H gel is also inserted by different hydrates such as AFt but it is not easy to distinguish. Some polymer films can be seen clearly.

When the hydration time lasts as long as 3 days, there is no great change of the structure in the control paste compared with the one at 1 day except that the whole structure becomes a little more compact (Figure 5(k)). However, in the modified paste AFt is more evident after 3 days than that after 1 day (Figure 5(l)). In addition, AFt and C-S-H gel penetrate with each other to develop the whole structure. The C-S-H gel and AFt in the modified paste look thicker and stronger compared with those in the control paste.

Another big difference between the modified paste and the control paste is the content and morphology of $\mathrm{CH}$. It is easy to find $\mathrm{CH}$ in the control paste after 3 days and its shape is very clear with an apparent sheet structure (Figure $5(\mathrm{~m})$ ). Though sheet-like $\mathrm{CH}$ also appears in the paste with SAE dispersion, its content is less and its surface is rougher with some hydrates on it (Figure 5(n)). This attributes to the effect of the SAE dispersion.

\section{Conclusions}

SAE dispersion does have effects on the early hydration of cement. The addition of SAE dispersion has little effect on the very initial period of cement hydration but prolongs the induction period, postpones and shortens the accelerating period, and inhibits the hydration during the decelerating and stable periods. The hydration heat and hydration degree of cement with SAE dispersion are less than the control ones within 3 days. The bigger $m_{p} / m_{c}$ is, the less hydration heat and hydration degree are.

SAE dispersion has big influence on the formation of the hydrates. It inhibits the formation of $\mathrm{C}_{4} \mathrm{AH}_{13}$ and thus $\mathrm{AFt}$, and more SAE dispersion brings stronger influence, but it enhances the stability of AFt, making its content higher than that in the control paste at relatively longer ages. AFt generation is controlled gradually by the reaction of $\mathrm{C}_{4} \mathrm{AH}_{13}$ generation with increasing SAE dispersion, but this is controlled by the reaction of $\mathrm{C}_{4} \mathrm{AH}_{13}$ consumption for the control paste. Besides, SAE dispersion retards and inhibits the formation of $\mathrm{CH}$ and $\mathrm{C}-\mathrm{S}-\mathrm{H}$ and also changes their morphology. It makes the C-S-H and AFt look thicker and stronger compared with those in the control paste after 3 days, and the surface of the $\mathrm{CH}$ becomes rougher with some other hydrates on it.

\section{Conflict of Interests}

The authors declare that there is no conflict of interests regarding the publication of this paper. 


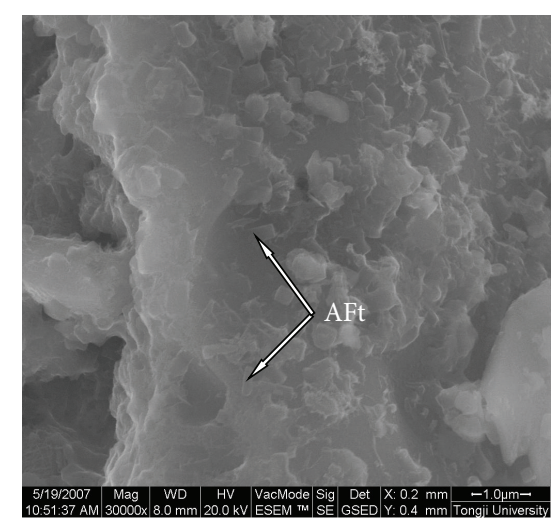

(a) Control paste, 10 minutes

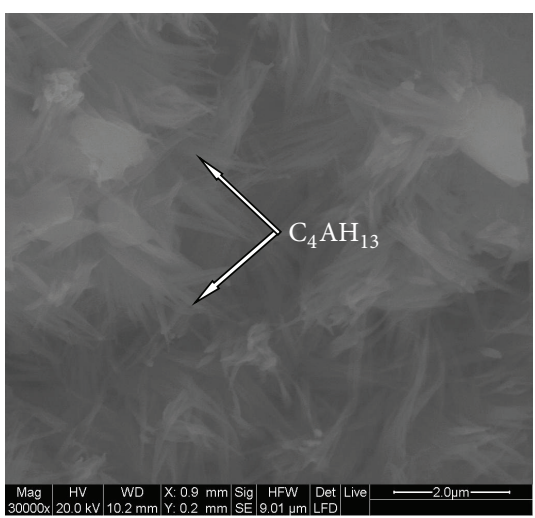

(c) Control paste, 1 hour

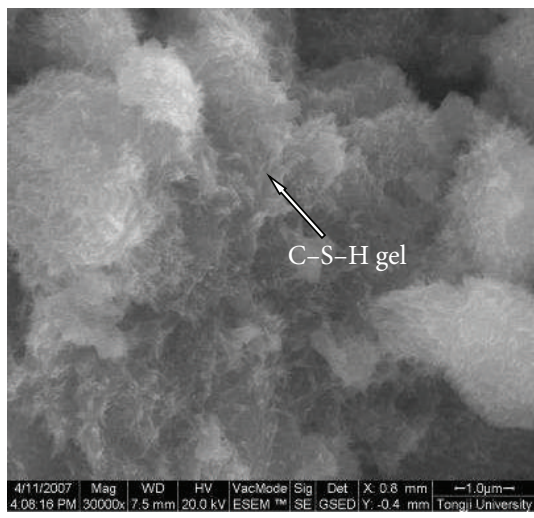

(e) Control paste, 6 hours

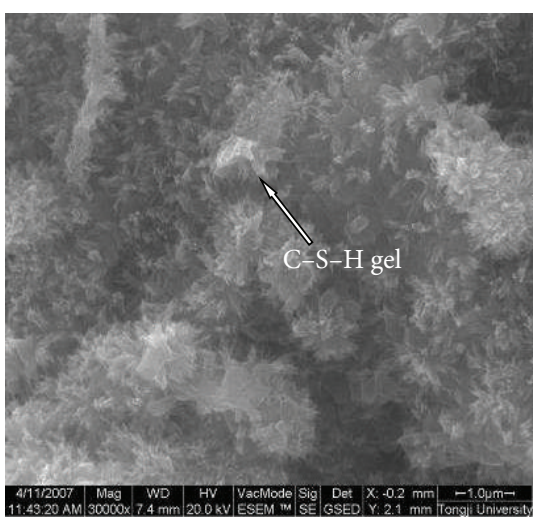

(g) Control paste, 12 hours

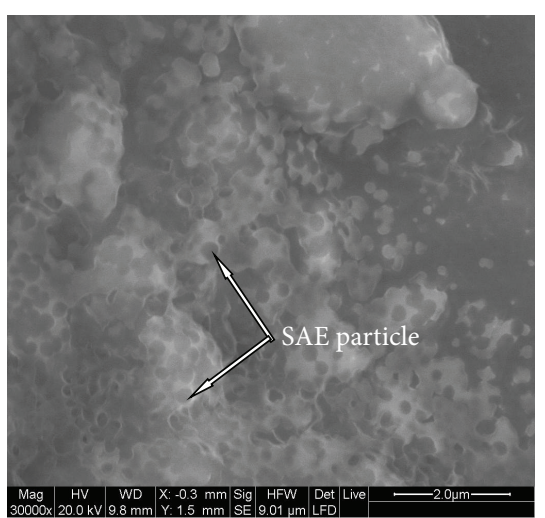

(b) $m_{p} / m_{c}$ of $10 \%, 10$ minutes

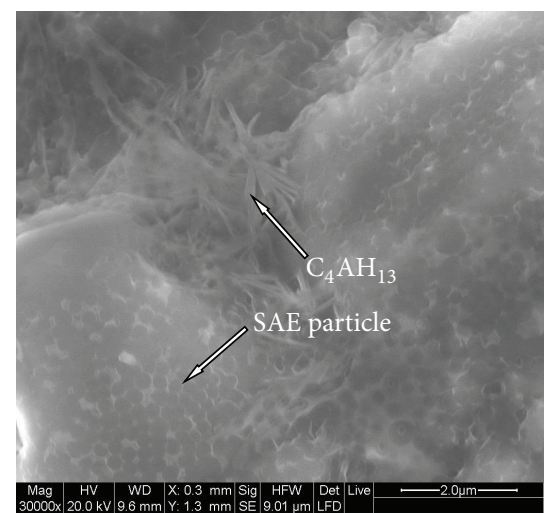

(d) $m_{p} / m_{c}$ of $10 \%, 1$ hour

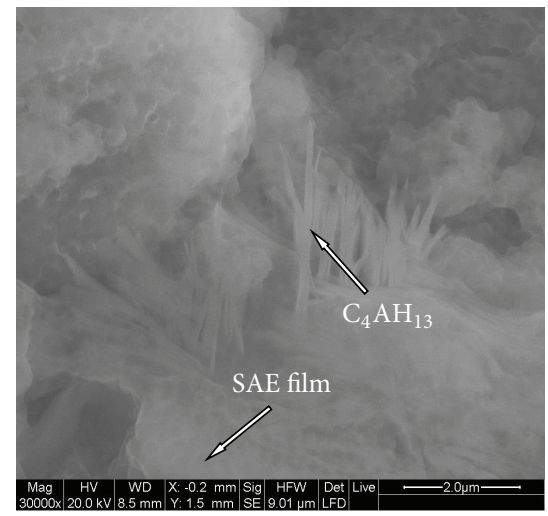

(f) $m_{p} / m_{c}$ of $10 \%, 6$ hours

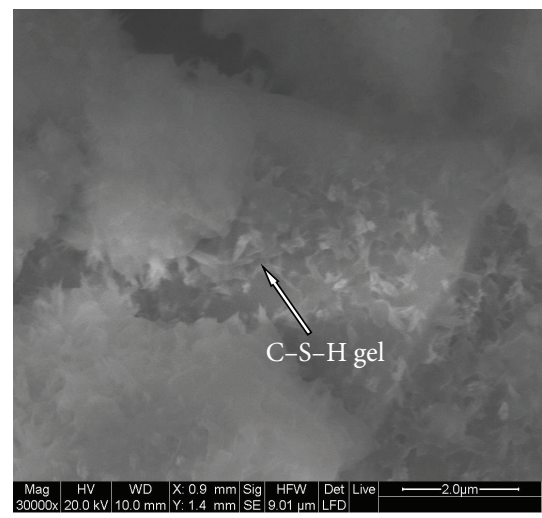

(h) $m_{p} / m_{c}$ of $10 \%, 12$ hours

Figure 5: Continued. 


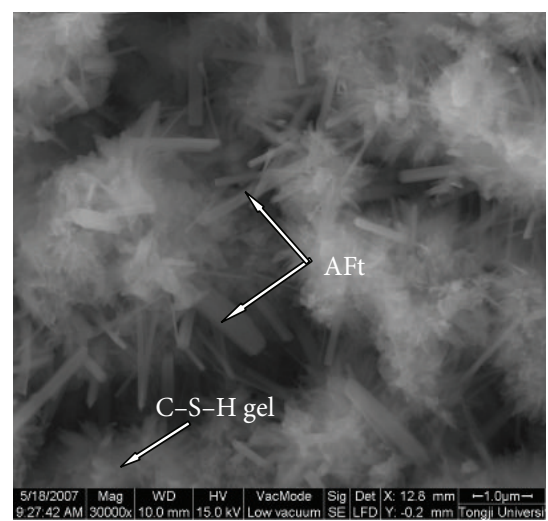

(i) Control paste, 1 day

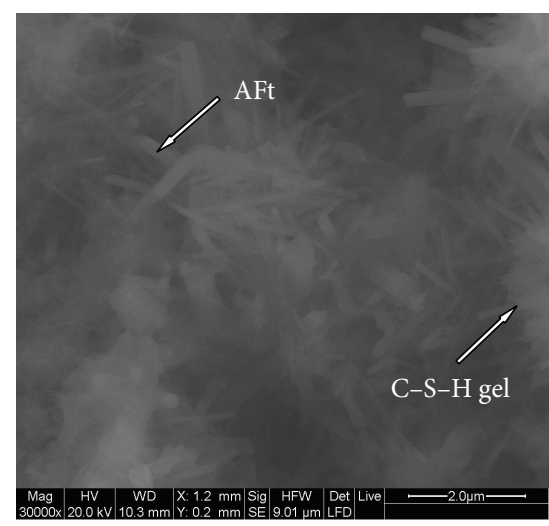

(k) Control paste, 3 days

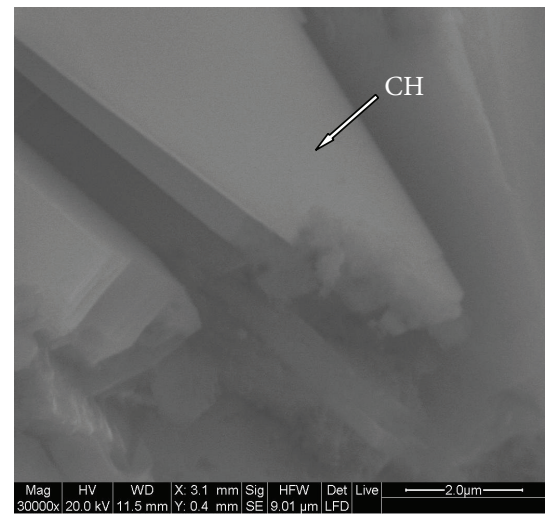

(m) Control paste, 3 days

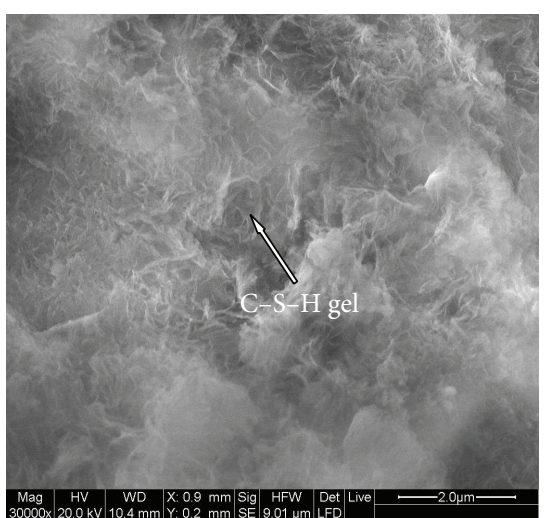

(j) $m_{p} / m_{c}$ of $10 \%, 1$ day

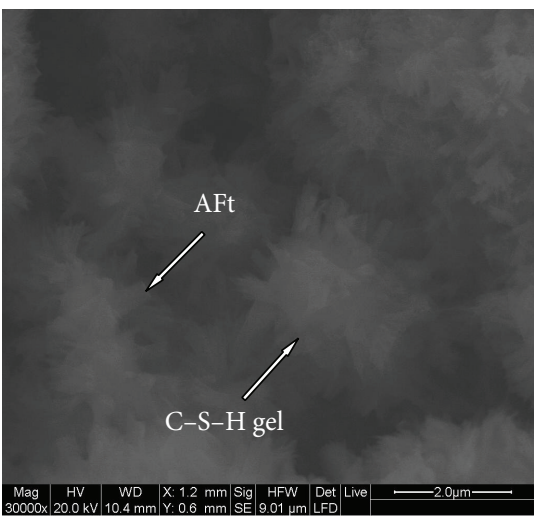

(l) $m_{p} / m_{c}$ of $10 \%, 3$ days

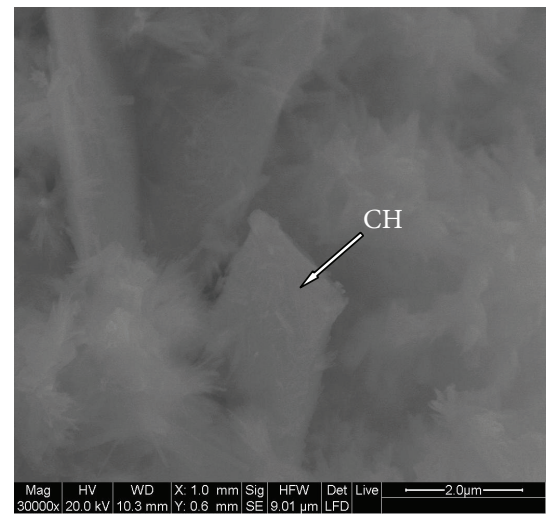

(n) $m_{p} / m_{c}$ of $10 \%, 3$ days

FIGURE 5: Second electron images of cement pastes in different ages observed by ESEM.

\section{Acknowledgments}

The authors acknowledge the financial support by the National Natural Science Foundation of China (51202162), the National Key Project of Scientific and Technical Supporting Programs Funded by Ministry of Science \& Technology of China (2012BAJ20B02), and the Bayer Science \& Education Foundation (TB20140006).

\section{References}

[1] S. Y. Zhong and Z. Y. Chen, "Properties of latex blends and its modified cement mortars," Cement and Concrete Research, vol. 32, no. 10, pp. 1515-1524, 2002.

[2] S. Zhong, M. Shi, and Z. Chen, "The AC response of polymercoated mortar specimens," Cement and Concrete Research, vol. 32, no. 6, pp. 983-987, 2002. 
[3] J. Mirza, M. S. Mirza, and R. Lapointe, "Laboratory and field performance of polymer-modified cement-based repair mortars in cold climates," Construction and Building Materials, vol. 16, no. 6, pp. 365-374, 2002.

[4] R. Wang and P. Wang, "Transverse deformation and ratio of compressive strength to flexural strength of SAE latex-modified mortar and their relationship," Journal of Building Materials, vol. 11, no. 4, pp. 464-468, 2008.

[5] J. Young, J. Seon, and K. Wan, "Bond strength of polymer cement slurry-coated rebar using EVA dispersion in cement concrete," in Proceedings of the 14th International Congress on Polymers in Concrete, pp. 175-184, Shanghai, China, April 2013.

[6] R. Wang, X. Shi, and P. Wang, "Recent research on polymermodified cement mortar in China," Advanced Materials Research, vol. 687, pp. 57-67, 2013.

[7] N. B. Singh and S. Rai, "Effect of polyvinyl alcohol on the hydration of cement with rice husk ash," Cement and Concrete Research, vol. 31, no. 2, pp. 239-243, 2001.

[8] E. Knapen and D. van Gemert, "Cement hydration and microstructure formation in the presence of water-soluble polymers," Cement and Concrete Research, vol. 39, no. 1, pp. 6-13, 2009.

[9] T. M. Piqué, H. Balzamo, and A. Vázquez, "Evaluation of the hydration of Portland cement modified with polyvinyl alcohol and nano clay," Key Engineering Materials, vol. 466, pp. 47-56, 2011.

[10] G. Zhang and P. Wang, "Effect of hydroxyethyl methyl cellulose on cement paste hydration," Journal of Tongji University, vol. 37, no. 3, pp. 369-373, 2009.

[11] A. M. Betioli, P. J. P. Gleize, D. A. Silva, V. M. John, and R. G. Pileggi, "Effect of HMEC on the consolidation of cement pastes: isothermal calorimetry versus oscillatory rheometry," Cement and Concrete Research, vol. 39, no. 5, pp. 440-445, 2009.

[12] A. M. Betioli, P. J. P. Gleize, V. M. John, and R. G. Pileggi, "Effect of EVA on the fresh properties of cement paste," Cement and Concrete Composites, vol. 34, no. 2, pp. 255-260, 2012.

[13] R. Wang and P. M. Wang, "Hydration of cement in the presence of SBR dispersion and powder," Key Engineering Materials, vol. 466, pp. 57-63, 2011.

[14] Z. Yang, X. Shi, A. T. Creighton, and M. M. Peterson, "Effect of styrene-butadiene rubber latex on the chloride permeability and microstructure of Portland cement mortar," Construction and Building Materials, vol. 23, no. 6, pp. 2283-2290, 2009.

[15] R. Wang, L. Yao, and P. Wang, "Mechanism analysis and effect of styrene-acrylate copolymer powder on cement hydrates," Construction and Building Materials, vol. 41, pp. 538-544, 2013.

[16] G. Zhang and P. Wang, "Effects of vinyl redispersible polymer on cement hydration products," Journal of Building Materials, vol. 13, no. 2, pp. 143-149, 2010.

[17] D. A. Silva, H. R. Roman, and P. J. P. Gleize, "Evidences of chemical interaction between EVA and hydrating Portland cement," Cement and Concrete Research, vol. 32, no. 9, pp. 1383-1390, 2002.

[18] P. Wang and E. Liu, "Study on properties of styrene-acrylate copolymer powder modified cement mortar," Journal of Building Materials, vol. 12, no. 3, pp. 253-265, 2009.

[19] R. Wang and P. M. Wang, "Function of styrene-acrylic ester copolymer latex in cement mortar," Materials and Structures, vol. 43, no. 4, pp. 443-451, 2010.

[20] P. Wang, S. Feng, and X. Liu, "Research approaches of cement hydration degree and their development," Journal of Building Materials, vol. 8, no. 6, pp. 646-652, 2005.
[21] N. R. Yang and W. H. Yue, Handbook of a Collection of Illustrative Plates of Inorganic Nonmetal Materials, Wuhan University of Technology Publishing Company, Wuhan, China, 2000. 

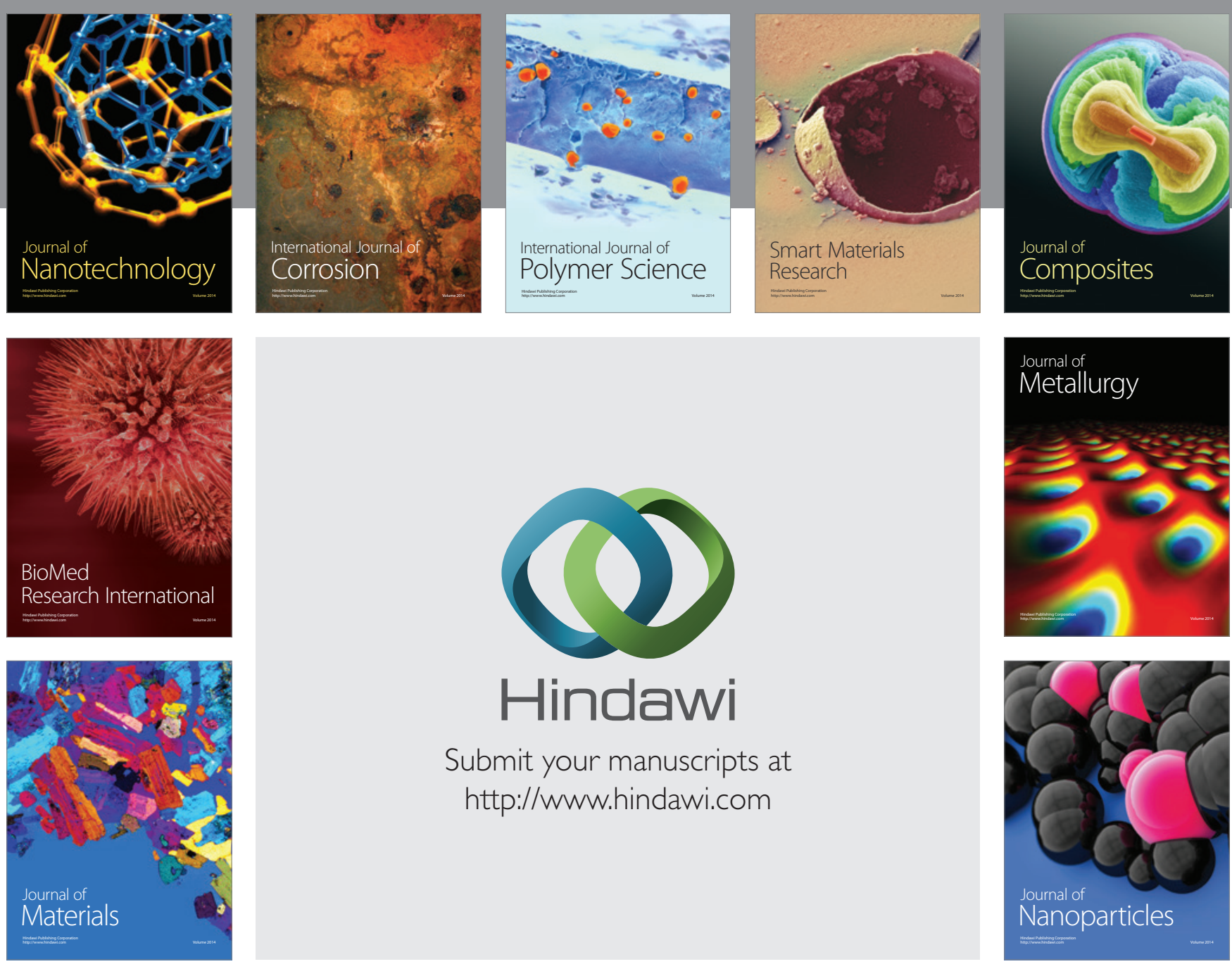

Submit your manuscripts at http://www.hindawi.com
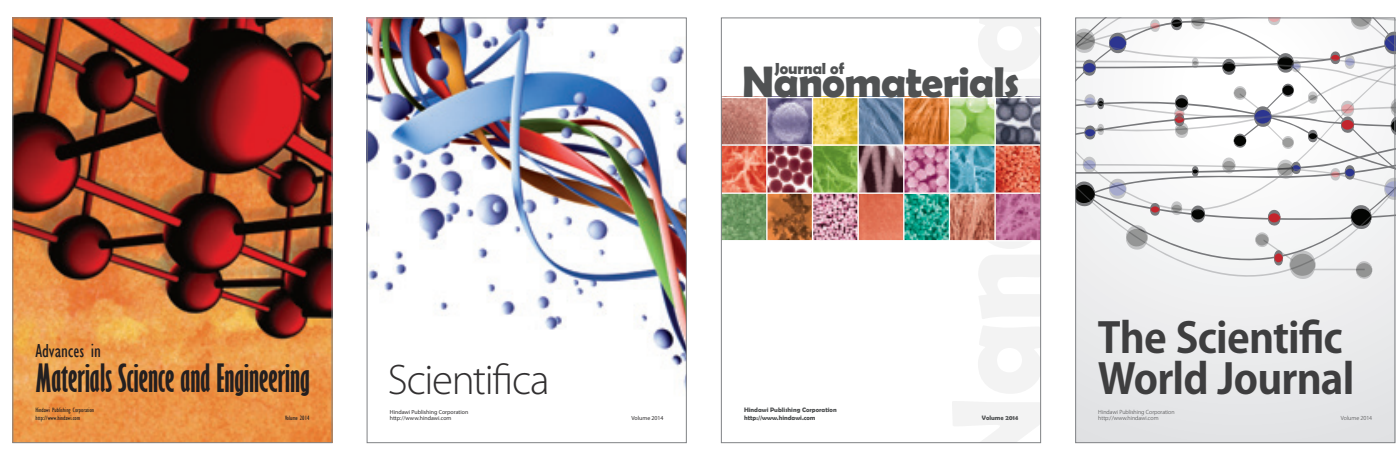

\section{The Scientific World Journal}
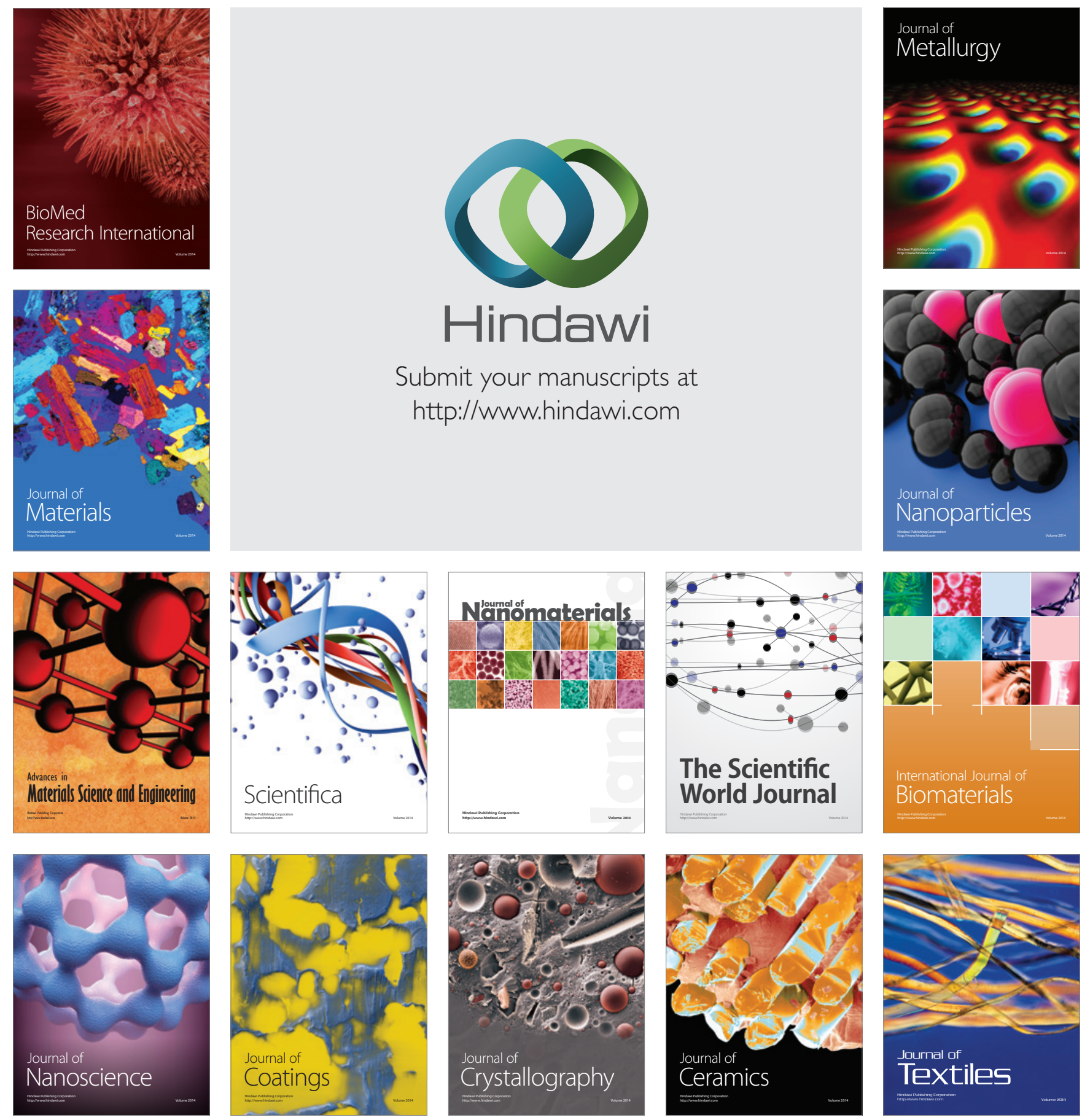